\title{
Donation after circulatory death donors in lung transplantation
}

\author{
Thomas M. Egan ${ }^{1}$, Benjamin E. Haithcock ${ }^{1}$, Jason Lobo ${ }^{2}$, Gita Mody ${ }^{1}$, Robert B. Love ${ }^{3}$, \\ John Jacob Requard III', John Espey ${ }^{1}$, Mir Hasnain Ali $^{1}$ \\ ${ }^{1}$ Department of Surgery, UNC at Chapel Hill, Chapel Hill, NC, USA; ${ }^{2}$ Department of Medicine, UNC at Chapel Hill, Chapel Hill, NC, USA; \\ ${ }^{3}$ Department of Surgery, Feinberg School of Medicine, Chicago, IL, USA; ${ }^{4}$ Lung Banks of America, Durham, NC, USA \\ Contributions: (I) Conception and design: TM Egan; (II) Administrative support: None; (III) Provision of study materials or patients: None; (IV) \\ Collection and assembly of data: All authors; (V) Data analysis and interpretation: All authors; (VI) Manuscript writing: All authors; (VII) Final \\ approval of manuscript: All authors. \\ Correspondence to: Thomas M. Egan, MD, MSc. Professor of Surgery, Adjunct Professor of Biomedical Engineering, 3040 Burnett-Womack Bldg., \\ University of North Carolina at Chapel Hill, Chapel Hill, NC 27500-7065, USA. Email: thomas_egan@med.unc.edu.
}

\begin{abstract}
Transplantation of any organ into a recipient requires a donor. Lung transplant has a long history of an inadequate number of suitable donors to meet demand, leading to deaths on the waiting list annually since national data was collected, and strict listing criteria. Before the Uniform Determination of Death Act (UDDA), passed in 1980, legally defined brain death in the U.S., all donors for lung transplant came from sudden death victims [uncontrolled Donation after Circulatory Death donors (uDCDs)] in the recipient's hospital emergency department. After passage of the UDDA, uDCDs were abandoned to Donation after Brain Death donors (DBDs) — perhaps prematurely. Compared to livers and kidneys, many DBDs have lungs that are unsuitable for transplant, due to aspiration pneumonia, neurogenic pulmonary edema, trauma, and the effects of brain death on lung function. Another group of donors has become available-patients with a devastating irrecoverable brain injury that do not meet criteria for brain death. If a decision is made by next-of-kin (NOK) to withdraw life support and allow death to occur by asphyxiation, with NOK consent, these individuals can have organs recovered if death occurs relatively quickly after cessation of mechanical ventilation and maintenance of their airway. These are known as controlled Donation after Circulatory Death donors (cDCDs). For a variety of reasons, in the U.S., lungs are recovered from cDCDs at a much lower rate than kidneys and livers. Ex-vivo lung perfusion (EVLP) in the last decade has had a modest impact on increasing the number of lungs for transplant from DBDs, but may have had a larger impact on lungs from cDCDs, and may be indispensable for safe transplantation of lungs from uDCDs. In the next decade, DCDs may have a substantial impact on the number of lung transplants performed in the U.S. and around the world.
\end{abstract}

Keywords: Donation after circulatory death; lung transplant; uncontrolled DCD; controlled DCD

Submitted Feb 09, 2021. Accepted for publication Feb 23, 2021.

doi: $10.21037 /$ jtd-2021-13

View this article at: http://dx.doi.org/10.21037/jtd-2021-13

What goes around comes around_Justin Timberlake, 2006

\section{Introduction}

In the early days of solid organ transplant, almost all organs were recovered after circulatory arrest from non-heartbeating donors (NHBDs). After years of experimental work, the first reported single lung transplant was performed by
Dr. Hardy in 1963 (1). This was controversial, because the recipient was a convicted felon with a large lung cancer whose death sentence was commuted to life in prison in exchange for agreeing to undergo a lung transplant. The donor succumbed from a myocardial infarction in the hospital's emergency department. No details of ischemic time or lung preservation were provided, but the recipient survived for 18 days, dying from renal failure and 
Table 1 Maastricht classification of NHBDs (10)

\begin{tabular}{lll}
\hline Category & Description & Place of death \\
\hline 1 & $\begin{array}{l}\text { Dead on arrival or dead } \\
\text { "in the field" }\end{array}$ & Outside hospital \\
2 & $\begin{array}{l}\text { Unsuccessful } \\
\text { resuscitation }\end{array}$ & $\begin{array}{l}\text { In hospital ward, ICU, } \\
\text { ER }\end{array}$ \\
3 & $\begin{array}{l}\text { Elective withdrawal of } \\
\text { ventilatory support }\end{array}$ & In ICU or OR \\
4 & $\begin{array}{l}\text { Cardiac arrest while } \\
\text { brain dead }\end{array}$ & In ICU or OR \\
\hline
\end{tabular}

The vast majority of NHBDs are Categories 1 and 2.

"malnutrition". In 1970, the accumulated world experience with lung transplantation was reviewed; 23 lung transplants had been reported; all donors were NHBDs (2).

To deal with the growing number of mechanically ventilated patients who appeared to have no brain function and yet had functioning circulation, a study was undertaken to make recommendations about neurologic criteria to define death. The second reason for the study was "Obsolete criteria for the definition of death can lead to controversy in obtaining organs for transplantation". The recommendations of the ad hoc Harvard Committee were published in 1968 (3). Eventually these recommendations were codified into law in the U.S. when Congress passed the Uniform Determination of Death Act (UDDA) in 1980 (4). In the U.S., "An individual who has sustained either (I) irreversible cessation of circulatory and respiratory functions, or (II) irreversible cessation of all functions of the entire brain, including the brain stem, is dead. A determination of death must be made in accordance with accepted medical standards." This was quickly adopted by most of the medical community (5). The interpretation of the UDDA has had some controversy, particularly with respect to resuming circulation after death is declared $(6,7)$. This has affected the recovery of other solid organs from NHBDs. This legal definition of death in the U.S. coincided with the establishment of cyclosporine as an effective immunosuppressant, approved for use in kidney, liver, and heart transplant by the U.S. Food and Drug Administration in 1983 (8). Once brain death became the established method for organ donation, the practice of recovering organs, including lungs from any type of
NHBD, was abandoned. For lungs, this may have been premature. None of the over 40 lung transplants attempted before 1983 that were reported resulted in immediate death from graft failure, despite their recovery from NHBDs (9).

Circumstances indicating the amount of ischemic time experienced by organs led to a classification of NHBDs (10) (Table 1). At another meeting to update the classification system, the terms controlled and uncontrolled Donation after Circulatory Determination of Death donors (cDCDD and $\mathrm{uDCDD}$ ) were adopted to distinguish organs recovered from Donation after Brain Death donors (DBDs) with a functioning circulation, from donors whose organs were recovered after death occurred and death was declared due to cessation of circulation. This can occur under different circumstances. In individuals with a devastating brain injury judged non-recoverable, life support can be voluntarily withdrawn, with the expectation of imminent death due to hypoxia and hypercarbia (asphyxiation) because of failure to adequately protect the airway and adequately ventilate the patient. If death occurs quickly, organs can be recovered expeditiously for transplant. These are referred to as "controlled" DCDDs (cDCDDs). If death occurs suddenly or unexpectedly, there is no time to prepare for organ recovery. These are uncontrolled DCDDs (uDCDDs). These deaths can occur inside or outside a hospital. The term DCD is an abbreviation of DCDD, proposed after the 6th International Conference in Organ Donation held in Paris in 2013 (11), and has been widely adopted. In this review, we will use the term DCD, and discuss transplantation of lungs from both controlled (c) and uncontrolled (u) DCDs. Kootstra's NHBD classification system (10) has been revised twice $(11,12)$, but universal adoption of either revision has not occurred. The classification system proposed at the Paris 2013 conference is shown in Table 2 (11).

Once the technical problems with airway healing were resolved, and patients with end-stage lung diseases were surviving lung transplants due to cyclosporine, there was explosive growth in lung transplant programs across the U.S. and around the world. By 1996, there were 75 centers reporting lung transplant activity to the United Network for Organ Sharing (UNOS) ${ }^{1}$, despite that only 815 lung transplants were performed that year (13). It was soon apparent that there weren't enough organ

\footnotetext{
${ }^{1}$ The United Network for Organ Sharing (UNOS) is a not-for-profit corporation that has held the U.S. contract to run the Organ Procurement and Transplant Network (OPTN) since its inception in 1983.
} 
Table 2 Modified Maastricht Classification of DCD (11)

\begin{tabular}{|c|c|c|}
\hline Category & Description & Details \\
\hline \multirow{2}{*}{ Category I Uncontrolled } & IA. Out-of-hospital & \multirow{2}{*}{$\begin{array}{l}\text { Sudden unexpected CA without any attempt of resuscitation by a } \\
\text { life-medical team }\end{array}$} \\
\hline & IB. In-hospital & \\
\hline Category II Uncontrolled & Witnessed cardiac arrest & \\
\hline Category III Controlled & Withdrawal of life-sustaining therapy & Planned withdrawal of life-sustaining therapy*; expected CA \\
\hline $\begin{array}{l}\text { Category IV Uncontrolled } \\
\text { Controlled }\end{array}$ & Cardiac arrest while life-brain dead & $\begin{array}{l}\text { Sudden CA after brain death diagnosis during donor life- } \\
\text { management but prior to planned organ recovery. }\end{array}$ \\
\hline
\end{tabular}

*, this category mainly refers to the decision to withdraw life-sustaining therapies. Legislation in some countries allows euthanasia (medically assisted $\mathrm{CA}$ ) and subsequent organ donation described as the fifth category. CA, circulatory arrest.

donors for the growing need, including lungs. In fact, only a portion of DBDs have lungs that are suitable for transplant. Many DBDs have poor lung function due to smoking, chest trauma, aspiration pneumonia after head injury (14), neurogenic pulmonary edema (15), pulmonary embolism (16), or pro-inflammatory responses due to brain death (17). The scarcity of suitable lungs for transplant has led to strict listing criteria $(18,19)$.

Despite a growing population, the number of DBDs is only increasing because of the opioid crisis (20-23). Care of head injured patients is improving (24), and it's possible that withdrawal of life support is being broached with family members before their head-injured family member progresses to brain death, resulting in more potential cDCDs, and fewer DBDs.

\section{cDCDs-early history}

At the University of Wisconsin (UW) work was continuing on the development of a preservation solution for organs from DBDs that would be safe even for heart and lung transplants. Experience and success with transplantation from controlled DCD abdominal organs at UW, led to the first clinical single lung transplant success at UW. One of us (TME) was performing canine experiments to demonstrate feasibility of successful lung transplant after recovery from uDCDs (25), while another (RL) was spending a month at UNC to observe how they ran their program and lab. Dr. Love returned to University of Wisconsin, where work was progressing on an improved organ preservation solution (UW), an innovative spirit, and success with cDCDs in kidney transplant (1992) (26) led to the first cDCD lung transplant by Love's group, re-transplanting a woman on ECMO for severe primary graft dysfunction (PGD) in 1993 (27). He continued to transplant lungs from these donors with acceptable outcomes (28).

\section{Potential number of cDCDs}

The number of potential lung cDCDs is difficult to ascertain, given lack of standardized practice in evaluating and recovering lungs from cDCDs by most American transplant centers. However, examining rates of cDCD lung transplants from other countries, the number of other solid organ transplants performed from cDCDs, and estimates of annual national fatality rates may be informative to estimate the potential number of suitable lungs from cDCDs. Establishing the incidence of suitable lungs from cDCDs would allow the transplant community to mobilize additional resources for evaluation of lungs in all cDCDs and facilitate implementation of routine utilization of cDCD lungs.

Data on rates of cDCD lung donations in the United States are limited to historical single institution series, registry reports, and the OPTN web site (Figure 1). In the early 1990 s, while $12.3 \%$ of all donors evaluated in one organ procurement organizations were DCDs, just one $(10 \%)$ of these was utilized for lung donation (26). A more recent study estimated $10 \%$ of in-hospital cardiac death decedents may be considered for lung donation (29). Rates of cDCD lung transplantation (4.8\% of all lung transplants in 2018), are still low in the U.S (30). Conversely, European and Australian centers report 25-40\% of lung transplants are done from cDCDs (31). Notably this represents a high 


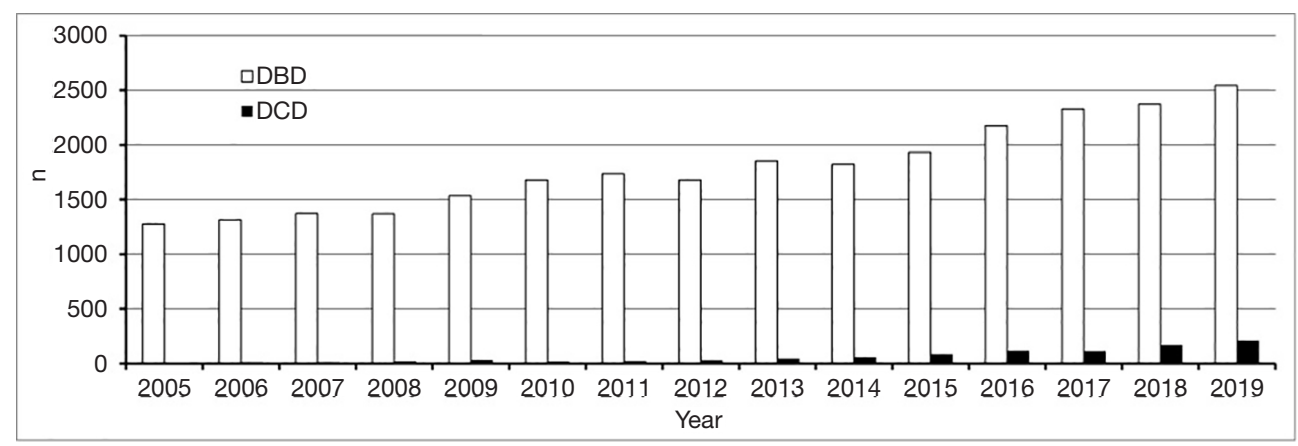

Figure 1 Number of Lung Donors per year. DBD, brain-dead donor; DCD, Donation after Circulatory Death Donor. Data obtained from OPTN Data Reports (https://optn.transplant.hrsa.gov/data/view-data-reports/).

rate of utilization of lungs from identified cDCDs (e.g., $39 \%$ of Australian DCDs donated lungs) (32). This may be attributable to a nationalized approach to organ sharing. A more recent analysis reported that in the U.S. between 2005 and 2019, 15,458 cDCDs had organs recovered. Of 30,916 lungs, $3.7 \%$ were used for transplant; recent transplant era was associated with significantly increased use (33).

Over 7 years, Mooney et al. determined lung utilization from cDCD donors was $2.1 \%$ compared to $21.4 \%$ for DBD donors in the U.S. (34). Population-based research studies on the rates of cDCD availability in general in the U.S. are more robust and suggest routine evaluation of cDCDs could have a significant impact (at least $22.7 \%$ more) on donor lung supply (35).

\section{Challenges to organ recovery from $c D C D s$}

Despite the Joint Commission and the OPTN requiring policies for organ procurement from cDCDs, there is little consistent guidance regarding the consent process and the timing of consent. Consensus is important as the process varies between DBD and cDCD donation. For DBDs, the donor is dead so the physicians are no longer involved in the conversation and consent is obtained postmortem by trained OPO personnel. In cDCD donation, the patient (through advanced directive) or the patient's family, has made the decision to withdraw care regardless of organ donation. If organ donation is desired, as noted by enrollment in a state registry, the need for confirmation from a person authorized to make decisions prior to the cDCD preservation process is controversial. In 48 of 50 states that have passed an amended Uniform Anatomical Gift Act (UAGA), permission for organ recovery from registered donors is not required. The UAGA was amended specifically to eliminate NOK input into the donation decision for registered organ donors (36). Many OPOs are not comfortable proceeding with organ recovery without NOK consent. It is imperative to ensure that the goal of organ transplantation does not negatively affect medical care for, or inappropriately hasten the death of a potential donor (37). However, there is an ethical argument to honor the wishes of the decedent who chose to be an organ donor.

An additional concern regarding cDCDs is cost and organ yield (38). Nationally, more than half of evaluated DCDs do not yield transplantable organs and the organ yield per DCD is approximately 1.93 as compared to 3.25 for DBDs (39). The OPO is responsible for all potential donor costs once consented for organ donation including ICU care, operating room (OR) fees, imaging, procedures, lab testing and so forth, and this cost varies greatly between donors and hospitals. Overall, the cost per organ from a DCD is $60 \%$ higher than from a DBD (39).

\section{Stakebolders in using organs from cDCDs}

A formal definition of stakeholders is: "individuals and organizations who are actively involved in the project, or whose interests may be positively or negatively affected as a result of project execution or successful project completion" [Project Management Institute (PMI $\left.\left.{ }^{\circledR}\right), 1996\right]$. The stakeholders in cDCDs are the recipient, the donor, the donor's family, the donor's caregivers, the hospital, the OPO, and the public. The recipient is generally not made aware of death criteria of their donor. Ensuring appropriate intent and consent is important for the donor and their family. The donor hospital has an important role in respecting the patient's wishes by making sure donation is made available in a timely manner. Additionally, as the 
donor hospital has an economic incentive to encourage donation as all costs are covered by the OPO, regardless of insurance, it must be clear through the process that there is no coercion. Some hospitals inform the OPO after a decision has been made to withdraw support at a particular time, leaving little time for the OPO staff to approach NOK for permission to recover organs. It is imperative to preserve the public trust in organ donation, especially cDCD donation, as lack of trust would reduce enrollment in donor registries and potentially decrease overall organ donation.

\section{Technical aspects of $\mathrm{DDCDs}$}

Prior to evaluation, the transplant team, including institutions and OPOs, should have established guidelines to avoid potential legal, ethical, religious, and cultural issues associated with the withdrawal of care of patients. The Australian programs have required a cDCD to be $<55$ years of age, where death is expected within $<90$ minutes of withdrawal of active treatment (40). Many American transplant programs accept organs from older donors.

When evaluating cDCDs for lung transplant, there are several factors that are important to consider. This includes, but is not limited to, the cause of death, prior chest surgery, history of lung disease (asthma, COPD, smoking, autoimmune and other diseases that might affect lung function), and pulmonary and non-pulmonary infections. Other concerns include the amount of hemodynamic support the donor requires and any other cardiac or thoracic pathology that would affect lung donation. The International Society of Heart and Lung Transplant (ISHLT) has established donor criteria (41). There have been several centers successful with cDCD using "extended criteria donors" $(42,43)$. The ideal situation involves cDCDs with anticipated death of less than 60 minutes. There have been studies that have determined that the extent of warm ischemia may play a role in post-transplant morbidity and mortality (44). In the era of ex-vivo lung perfusion (EVLP), this risk may be minimized.

After withdrawal of life support, the patient is given 60-90 minutes for cardiac arrest to occur. If this does not occur, the patient is returned to the ICU, or moved to a regular room. If cardiac arrest occurs, the appropriate clinician certifies death 5 minutes later. After death declaration, the cDCD is then moved into the OR. Some centers place the potential donor in the OR for death to occur there. At UNC, the cDCD is given 50,000 U of heparin through a central venous catheter followed by 20 cardiac compressions to ensure heparin circulation. Some centers administer heparin before withdrawal of support. The decedent's endotracheal tube either remains in place and the endotracheal balloon is inspected to remain inflated to prevent aspiration. If the endotracheal tube has to be re-inserted after declaration of death, this should be done to ventilate lungs and to minimize aspiration. Once in the $\mathrm{OR}$, the patient is resumed on mechanical ventilation. If bronchoscopy has not been performed prior, it is performed at this time for inspection. A sternotomy is performed and the pulmonary artery is cannulated with instillation of 4 liters cold low potassium dextran solution preceded by $500 \mu \mathrm{g}$ prostaglandin E1. The lungs are inspected for evidence of trauma or other anatomic abnormalities. A $500 \mathrm{ml}$ retrograde flush of cold low potassium dextran solution is given through each pulmonary vein as for standard DBD lung recovery. The lungs are removed and stored in cold storage solution on ice.

\section{Results of lung transplant from cDCDs}

Multiple studies have compared survival of recipients of lungs from cDCDs and DBDs at 1,3 , and 5 years post lung transplant. A meta-analysis by Krutsinger et al. included data from 6 studies, including $271 \mathrm{cDCD}$ recipients and 2,369 DBD recipients, and found no difference in mortality at 1 year (31). Like Krutsinger et al., Inci et al. from Zurich Switzerland also found no difference in survival rates (45). Survival rates for cDCD recipients were $100 \%$ and $80 \%$ at years 1 and 3, respectively, while survival rates for DBD recipients were $85 \%$ and $69 \%$ at the same time points. Recipient survival at 1, 3, and 5 years was reported by De Oliveira et al. (Dr. Love was the senior author) (46). Their study included data collected over a long time frame (January 1993-April 2009) and included 18 cDCD recipients out of 424 total lung transplants. Survival rates were not different between $\mathrm{cDCD}$ and DBD recipients at 1,3 , or 5 years.

A retrospective study by Van Raemdonck et al. utilized data from the ISHLT Thoracic Transplant Registry (47). Data for all cDCD lung transplants performed at 22 sites (8 US; 1 Canada; 9 Europe; 4 Australia) between January 2003 and June 2017 were included and compared to registry data for DBD lung transplants during the same time frame. Ultimately, the cohort included 11,516 lung transplants, including 1,090 from cDCDs. There was no difference in 1-year survival rates $89 \%$ in cDCD group and $88 \%$ in 
DBD group) or 5 -year survival rates (63\% in cDCD group and $61 \%$ in DBD group). This study is the largest to date reporting on lung transplant survival from $\mathrm{cDCDs}$, and more evidence is expected to become available as the use of DCD organs becomes more popular and more centers join this ISHLT registry.

None of the cited studies found a significant difference in patient survival rates at 1,3 , or 5 years post lung transplant. Similarly, there were very few significant differences in other outcomes assessed by the authors. All studies failed to find a difference in graft dysfunction between recipients of $\mathrm{cDCD}$ and DBD lungs.

The available literature supports using lungs from cDCDs to expand the lung donor pool. Recipients of lungs from cDCDs or DBDs appear to experience similar outcomes. There is growing utilization of lungs from cDCDs, particularly outside the US. Better utilization of lungs from cDCDs could greatly increase availability of donor lungs, reducing waiting time and waitlist deaths.

\section{uDCDs}

Among solid organs that are transplanted, the lung is unique. The lung does not rely on perfusion for cellular respiration. Most cells in the lung are exposed to air. Even blood in the arterial circulation is $75 \% \mathrm{O} 2$-saturated. When sudden death occurs, EMS personnel begin cardiopulmonary resuscitation (CPR), and usually insert an airway, either endotracheal intubation or a Brooke airway, and administer oxygen, hoping to re-establish circulation. At rest, only about $25 \%$ of the vascular gas exchange surface area of the normal lung is perfused, and the remainder, which contains blood, doesn't clot. In a stringent canine single lung transplant model, we showed that lungs could be recovered one hour after circulatory arrest and transplanted with excellent gas exchange. Recipients were ventilated with $40 \%$ oxygen. One hour after left lung transplant, the recipient's right pulmonary artery was ligated, and recipients were followed for 8 hours, dependent for survival solely on the newly transplanted lung receiving the entire cardiac output. Recipients of lungs recovered one hour postmortem did well. Recipients of lungs recovered 2 hours post mortem did not fare as well; 3 of 6 survived. Recipients of lungs recovered 4 hours post mortem had poor oxygenation with 2 of 6 surviving 8 hours (25). However, if the deceased donor was ventilated after cardiac arrest, lungs could be recovered 4 hours post-mortem with good gas exchange and survival using the same model (48), or a model of bilateral lung transplant (49). We then showed that lung parenchymal cells lived for hours after circulatory arrest in a rat; cell death, assessed by trypan blue exclusion (50), and ultrastructural damage by electron microscopy (51) was delayed by post-mortem ventilation. Subsequently, Steen performed a single lung transplant using a lung recovered from an uDCD in his emergency department after ex-vivo lung perfusion (EVLP) (52), and Varela's group in Madrid Spain began to transplant lungs recovered from sudden death victims (53).

\section{Impact of uDCDs on the lung donor pool}

The number of people who die due to brain death or severe brain injury in an intensive care unit while mechanically ventilated is very small. Most people die suddenly, outside of a hospital, or from chronic illness or cancer. The size of the donor pool from uDCDs is unknown, but likely very large. As of 2003 , there were over $3 / 4$ million sudden deaths/year in the U.S. from all causes (Table 3) (54). Since then the National Center for Health Statistics stopped reporting the number and causes of sudden death, so these estimates have changed. The annual number of motor vehicle crash victim deaths has come down to 16,000 . The American Heart Association estimates there are 440,000 out-of-hospital cardiac arrest victims annually; 211,000 are treated by EMS personnel. The median age is 60 . There are 187,000 fatalities. There are over 200,000 estimated inhospital cardiac arrests annually with 152,000 fatalities (55). This could provide a substantial number of uDCD lung donors. In the U.S., organs are not recovered for transplant from uDCDs because lack of circulation quickly damages the organs (except lungs). If suitable lungs could be recovered from even a small percentage of uDCDs, the impact on LTX would be substantial. A recent analysis estimated the potential number of lungs that might be suitable for transplant from uDCDs was conservatively as many as 10,000 per year (56). However, this analysis did not consider the impact of sudden deaths outside of hospital, or among the in-patient pool of sudden death victims (57). So the real number of suitable lungs from uDCDs is likely very large.

In 2013, one of us (TME) received a NIH grant (1UM1HL113115) (58) to conduct a Phase II clinical trial to recover lungs from uDCDs, assess them by EVLP and ex-vivo CT scan, and offer them for transplant to consented patients at UNC Hospitals and Duke University Medical Center (ClinicalTrials.gov NCT01615484). The catchment 
Table 3 Most common causes of sudden death each year in the U.S. (54)

\begin{tabular}{lc}
\hline Cause of death & $\mathrm{n}$ \\
\hline Sudden cardiac & 400,000 \\
CV disease & 157,000 \\
Accidents, all & 106,000 \\
MVC's & 44,000 \\
Firearms & 750 \\
Suicide & 30,600 \\
By firearms & 17,000 \\
Homicide & 17,000 \\
By firearms & 11,600 \\
Total sudden deaths & 784,000
\end{tabular}

area was relatively suburban and included Raleigh NC. Although there were a large number of potential uDCDs under age 66, [500] over 31 months, there were several logistic and medical rule outs. Lungs from $31 \mathrm{uDCDs}$ were recovered and 18 had EVLP. Two lung blocks were judged suitable for transplant, but none were transplanted (59).

The most common causes of annual deaths in the United States in 2017 were heart disease $(647,457)$, cancer $(599,108)$, and accidents $(169,936)(60)$. Of these, sudden death victims from cardiac arrest and trauma, both in and out of hospital, can be considered for lung donation. However, the potential lung donor pool is further narrowed by evaluation of quality using usual clinical criteria and detailed medical and social history including age, smoking history, and comorbidities. In addition, the issue of consent both from the decedent ("first person") and NOK for a sudden death victim must be considered. Finally, the accessibility of rural decedent EMS and procurement personnel may preclude donation from a small proportion of the general population. Our field-based clinical trial work showed a lower actual number of suitable, recoverable DCD lungs than anticipated, primarily due to logistical concerns including missing consent and additionally due to smoking and other lung disease history and cause of death (e.g., pulmonary embolism) that lead to poor lung quality (59). Nonetheless, recent experience in Canada resulted in 5 successful lung transplants from uDCDs, and suggested that $16.7 \%$ of uncontrolled consented donors can be used for lung transplantation (61). In Canada, the need for consent from NOK for organ recovery is preferred, but in almost all states in the U.S. registration as an organ donor is sufficient for recovery (62). All told, once logistic concerns are addressed, routine lung donation after uncontrolled circulatory death could solve the lung donor shortage.

\section{Stakebolders in the process of uDCDs}

Primary stakeholders are entities that are the sources of potential uDCDs and must agree to participate in an $\mathrm{uDCD}$ program, which include:

* OPOs must establish call centers to receive reports about deaths at acute care hospitals or from EMS to triage them for potential organ, eye and/or tissue donation. OPOs must decide their policy about recovering organs for possible transplant from registered organ donors without communicating with or finding NOK. In North Carolina, the attorney general's (AG's) office opined that our $\mathrm{OPO}$ was obliged to recover lungs from registered organ donors if transplant was a possibility, even in the case of a clinical trial. Our OPO executives and their Board of Directors felt that because this was "research", the AG's opinion did not apply.

* Hospitals must report all deaths to the regional OPO, based on US Federal law, again to be screened as potential donors. For lung donation from uDCDs, this reporting must occur within minutes of death, so the OPO can determine if the decedent is a registered organ donor, and if not, to help identify NOK to seek permission for lung donation.

* EMS may be a large source of sudden death victims that may qualify as uDCDs. Increasingly in the U.S., if a cardiac rhythm isn't established, EMS staff declare death and don't transport the patient to a hospital performing cardiopulmonary resuscitation (CPR). These deaths can be reported to the OPO Call Center. Whether the decedent can be ventilated until NOK consent is obtained depends on the state's AG interpretation of the UAGA.

Ancillary stakeholders are those needed to support the uDCD referral, consent and recovery process, which include:

* The State AG Office may have to define the operational policy for use of First Person Authorization (organ donor registration) in which an individual makes an antemortem decision to donate organs and/or tissues at the time of death.

* Law enforcement (District Attorneys and Police Departments) are involved in investigation and 
possible criminal prosecution of actions following a sudden death. These agencies must be educated as to how uDCD programs work and promulgate death investigation policies that will support the $\mathrm{uDCD}$ program. DA policies will then flow down to educate police departments in affected jurisdictions. Police departments have a role in this process since they may be called to the sudden death scene to evaluate the circumstances regarding the possibility of foul play that could be the basis for criminal investigation.

* Medical Examiners (ME)/Coroners Offices in most jurisdictions, must authorize removal of the body for any purpose, including organ recovery. If EMS declares death in the field, the ME is contacted by OPO staff. If there is concern that the death may not be due to natural causes, then the ME might choose not to release the body. An autopsy can still occur after lung removal (or organ recovery from a DBD). Opening the chest might reveal the cause of death, as it did in over half of the cases in our study. Blood and urine can be recovered for toxicology studies if requested by the $\mathrm{ME}$ at the time of lung recovery.

* Hospital Clergy at one hospital grieving with family members prevented NOK from taking calls from our OPO to explain the study and obtain permission to move the decedent for lung recovery. This required visiting the cleric offices to provide information about the project. After hearing our explanation to engage their assistance, they explained to family members that the call was important to take and interrupt their grieving process. Instead of being detrimental, they became allies.

* Patient Concerns, Barriers to Consent: uDCD donors are a novel approach to increase the lung donor pool. At UNC, patients were approached for consent at the time of listing for our uDCD study. Approaching recipients regarding an experimental donor is challenging. Concerns expressed by recipients and families were mostly about suitability of lungs because the program was experimental. There were few published reports of successful outcomes following lung transplant from uDCDs. Earlier reports from Spain suggested a higher risk for recipients of lungs from $\mathrm{uDCD}$ donors (63). This was modified as our clinical trial began, suggesting that lungs from uDCDs in Madrid had similar outcomes to conventional donors if EVLP was suitable (64). These and other new data may improve enthusiasm and recipient consent rates.

\section{Technical aspects of lung recovery from $u D C D s$}

After a witnessed cardiac arrest, out of hospital EMS initiates CPR according to national/international protocols with the goal of returning spontaneous circulation. Some EMS organizations only transport patients to hospital if a rhythm is established with palpable pulses. If a rhythm can't be established, EMS may declare death in the field. This is occurring increasingly based on recommendations of EMS and ED physicians $(65,66)$. Otherwise, CPR is continued, and patients are transported to a hospital. If CPR is initiated by individuals who find an unresponsive individual, EMS usually continues CPR. These are unwitnessed arrests. In our limited experience, EVLP of these lungs was not successful.

In Spain, the uDCD protocol is activated once the irreversibility of cardiac arrest has been determined outside hospital. Death is not declared, and the patient is transferred with CPR continued using a CPR machine to a hospital with a therapeutic purpose (67). Death is certified by physicians independent from the EMS and donor coordinator. This process involves ensuring no spontaneous circulation and respiration for 5 minutes (68). Depending on the country, cardiac compression and ventilation continues to preserve organs until legal permission for insitu organ preservation is obtained $(67,69)$. Heparin is then administered. In-situ methods of organ preservation is then initiated. In Spain, $24 \mathrm{~F}$ tube thoracotomies are placed into both pleural spaces, typically through the $2^{\text {nd }}$ intercostal space mid clavicular line. A cold low potassium dextran solution is instilled at $4{ }^{\circ} \mathrm{C}$ for topical cooling (3-4 L per hemithorax) to allow for both topical cooling and lung collapse. An esophageal temperature probe is used to ensure a temperature of $20^{\circ} \mathrm{C}$. If the abdominal team uses normothermic regional perfusion (NRP), 2 separate tube thoracotomies may be inserted and allow for recirculation of the cold preservative solution to maintain the targeted temperature. The endotracheal tube balloon must be up to minimize aspiration and vented to air to allow for intrapulmonary air to escape. Animal studies determined that cooling the pulmonary graft inside the cadaver is preferred to ventilation in a non-heart beating donor protocol in order to preserve function for up to 6 hours (70). Bronchoscopy is performed to evaluate airway anatomy and determine if aspiration has occurred. A sternotomy is performed and the lungs are inspected. If deemed suitable, 
the lungs are flushed both antegrade and retrograde with cold low potassium dextran solution. The heart-lung block or the lungs alone are removed.

We ventilated our uDCD donors before lung recovery, as did the program in Milan (71). They had a successful outcome despite over 5 hours of ischemia (72). We evaluated all lungs recovered from uDCD donors with EVLP, but this is not universally used.

A substantial logistical problem was the need for sudden mobilization of surgeons and OPO personnel to recover lungs from an uDCD donor who suddenly becomes available. Blood is drawn at the time of organ recovery for $\mathrm{ABO}$ typing and serologies. The OPO requirement for serologies performed by nucleic acid testing (NAT) added considerable cold ischemic time for our lung blocks, that appeared to be well tolerated.

\section{Results of lung transplant from uDCDs}

As mentioned, the first isolated lung transplants were all from uDCDs. In the modern era, Steen performed the first single lung transplant from an uDCD after EVLP (52). The patient recovered and was on room air when she became ill, and died from sepsis due to ascending cholangitis. Unfortunately, that experienced ended his uDCD program. Although the results of early experience with uDCD donor lung transplants appeared to be inferior to DBDs (63), more recent studies in Madrid showed no difference in survival rates compared to transplants from DBDs, perhaps due to the use of EVLP (64). Another study from a smaller lung transplant program in Spain reported excellent results with uDCD donors $(73,74)$, even though EVLP was only used in lungs from $2 \mathrm{uDCDs}$. Only one of 9 recipients died with follow-up beyond 5 years. Valenza and colleagues from Milan reported a successful lung transplant from an uDCD donor (71), with over 5 hours of warm ischemia (72). Healey et al. from Toronto reported very good results in their first 5 recipients of lungs recovered from uDCDs, assessed by EVLP (61). Sixteen lung blocks were recovered, 14 had EVLP, and 5 lung transplants were performed with one death in the first year. Although there were 147 sudden death victims over 39 months with substantial logistical issues, these additional lung donors all came from one suburban hospital, in a metropolitan area of 6 million people (62). This underscores the potential number of lungs from uDCDs, highlighted in the accompanying editorial (75). The Milan lung transplant group reported another successful lung transplant from an
uDCD donor, performed after 17 hours of EVLP, necessary to rule out leukemia in the donor (76). This experience implies that prolonged EVLP may be well tolerated, making EVLP a potential platform for lung therapy before transplant $(77,78)$. The bottom line? The number of lungs that might be recovered from uDCDs is unknown. With an organized approach, it would easily exceed the number of current DBD donors.

\section{Ethical and legal issues of lung recovery from uDCDs}

Different countries and cultures have different laws and beliefs/feelings about death. In the U.S. death was legally defined by the UDDA (described above). Shortly after the UDDA became law, Dr. Bernat expressed concern about the definition of death (6). He chaired a committee commissioned by HRSA to provide advice about proceeding with organ recovery from cDCD donors (7). This panel recommended the " 5 minutes handsoff" policy after death declaration before members of the transplant team could touch the decedent. HRSA accepted these recommendations, which have become policy in most hospitals. Dr. Bernat was subsequently asked to chair a committee to recommend policies for uDCDs (79). This panel was more contentious, with some members resigning and offering alternative opinions (80). Based on their interpretation of the UDDA, Dr. Bernat's panel proposed that resumption of ventilation or circulation after death declaration was not allowed. This has been contentious $(80,81)$ and remains unresolved. HRSA did not adopt this panel's recommendations, which included that the "hands-off" period for cDCD donors should be extended to 7 minutes. What has never been addressed is the ethical obligation to honor the wishes of the registered organ donor. If resumption of circulation and ventilation after death would allow recovery of abdominal organs and lungs for transplant, isn't it appropriate to do this? This is consistent with a survey conducted 10 years ago (82), and with one we performed after our uDCD lung study (83). A recent paper by Wall's group argues that lung recovery in the U.S. is ethical (69). In Spain, EMS providers perform CPR at the scene. If a rhythm is not obtained, in an ageappropriate patient, CPR will continue en-route to the nearest hospital. After the treating team has determined that CPR is unsuccessful, the patient is considered a potential uDCD. The EMS will contact the donor coordinator at the receiving hospital to review an initial inclusion criteria already established. NOK is contacted for permission to 
recover organs. The results, ethical, and legal issues have been well articulated (84).

\section{The role of EVLP in assessing lungs from DCDs}

There is little doubt that lungs recovered from uDCD donors should be assessed with EVLP before transplant, unless warm ischemic time is very short $(85,86)$. The FDA would not allow us to transplant lungs recovered from uDCDs without EVLP. The criteria for using EVLP on lungs recovered from cDCDs is unclear. Having EVLP available might allow lung assessment after longer intervals of low blood pressure or hypoxia, and may result in use of more lungs from cDCD donors (85). A review of the ISHLT DCD database indicated that EVLP was used in only $12 \%$ of DCD donors (47). The largest lung transplant program with the most experience in the world with EVLP reported using EVLP for about one half of lungs recovered from cDCD donors (87), without rigid criteria for EVLP use. Recipients of cDCD lungs had similar outcomes to recipients of DBD, with or without EVLP.

\section{Summary and conclusions}

It is somewhat ironic that organs from DCDs are making a "comeback". Before brain death was defined, organ transplants were performed from sudden death victims. Aside from the opioid crisis, it appears that the number of DBDs per capita is declining.

Future directions to increase all donors:

* Increasing numbers of first-person consented donors (58\% registered in U.S.) (88), and appropriate use of first-person consent.

* Decreasing rates of smoking: $21 \%$ in 2005 to $14 \%$ in 2018 (89).

* Extending donor criteria: e.g., lungs from Hepatitis C infected donors (90).

* EVLP to increase yield of lungs from conventional donors.

There is increasing use of organs, including lungs, from DCD donors. There are large discrepancies between countries on the utilization of organs for transplant from DCD donors. A recent survey from 35 European and western Asian countries, including Russia and Israel, documented that DCD donors are used in 18 of 35 countries: eight have both $\mathrm{cDCD}$ and uDCD programs, 4 only cDCD and 6 only uDCD (68). Outcomes for recipients appear to be as good, and in some centers, better than transplant from DBDs. The logistical, ethical, and legal challenges surrounding the routine recovery of viable organs from uDCDs may be daunting, but this is a potentially very large donor source that could have a major impact on lung and other organ donor numbers.

\section{Acknowledgments}

Dr. Egan was supported in part by the UNC Lung Transplant Research Fund, with generous contributions from James Ferguson and his family, and John Doherty.

Funding: None.

\section{Footnote}

Provenance and Peer Review: This article was commissioned by the Guest Editor (Jonathan D'Cunha) for the series "Lung Transplantation: Past, Present, and Future" published in Fournal of Thoracic Disease. The article has undergone external peer review.

Conflicts of interest: All authors have completed the ICMJE uniform disclosure form (available at http:// dx.doi.org/10.21037/jtd-2021-13). The series "Lung Transplantation: Past, Present, and Future" was commissioned by the editorial office without any funding or sponsorship. All authors have no other conflicts of interest to declare.

Ethical Statement: All authors are accountable for all aspects of the work in ensuring that questions related to the accuracy or integrity of any part of the work are appropriately investigated and resolved.

Open Access Statement: This is an Open Access article distributed in accordance with the Creative Commons Attribution-NonCommercial-NoDerivs 4.0 International License (CC BY-NC-ND 4.0), which permits the noncommercial replication and distribution of the article with the strict proviso that no changes or edits are made and the original work is properly cited (including links to both the formal publication through the relevant DOI and the license). See: https://creativecommons.org/licenses/by-nc-nd/4.0/.

\section{References}

1. Hardy JD, Webb WR, Dalton ML, et al. Lung homotransplantation in man. JAMA 1963;186:1065-74. 
2. Wildevuur CR, Benfield JR. A review of 23 human lung transplantations by 20 surgeons. Ann Thorac Surg 1970;9:489-515.

3. A definition of irreversible coma. Report of the Ad Hoc Committee of the Harvard Medical School to Examine the Definition of Brain Death. JAMA 1968;205:337-40.

4. Uniform determination of death act, (1980). Available online: https://www.uniformlaws.org/ HigherLogic/System/DownloadDocumentFile. ashx? DocumentFileKey=341343fa-1 efe-706c-043a9290fdcfd 909.

5. Guidelines for the determination of death. Report of the medical consultants on the diagnosis of death to the President's Commission for the Study of Ethical Problems in Medicine and Biomedical and Behavioral Research. JAMA 1981;246:2184-6.

6. Bernat JL, Culver CM, Gert B. Defining death in theory and practice. Hastings Cent Rep 1982;12:5-8.

7. Bernat JL, Capron AM, Bleck TP, et al. The circulatoryrespiratory determination of death in organ donation. Crit Care Med 2010;38:963-70.

8. Kolata G. FDA speeds approval of cyclosporin. Science 1983;221:1273.

9. Egan TM, Kaiser LR, Cooper JD. Lung transplantation. Curr Probl Surg 1989;26:673-751.

10. Kootstra G, Daemen JH, Oomen AP. Categories of nonheart-beating donors. Transplant Proc 1995;27:2893-4.

11. Thuong M, Ruiz A, Evrard P, et al. New classification of donation after circulatory death donors definitions and terminology. Transpl Int 2016;29:749-59.

12. Detry O, Le Dinh H, Noterdaeme T, et al. Categories of donation after cardiocirculatory death. Transplant Proc 2012;44:1189-95.

13. Cooper J, Egan T. History of Lung Transplantation. In: Vigneswaran W, Garrity E, editors. Lung Transplantation. New York, NY: Taylor \& Francis/CRC Press; 2015. p. 3-12.

14. Hsieh AH, Bishop MJ, Kublis PS, et al. Pneumonia following closed head injury. Am Rev Respir Dis 1992;146:290-4.

15. Rogers FB, Shackford SR, Trevisani GT, et al. Neurogenic pulmonary edema in fatal and nonfatal head injuries. J Trauma 1995;39:860-6.

16. Ware LB, Fang X, Wang Y, et al. High prevalence of pulmonary arterial thrombi in donor lungs rejected for transplantation. J Heart Lung Transplant 2005;24:1650-6.

17. Avlonitis VS, Fisher AJ, Kirby JA, et al. Pulmonary transplantation: the role of brain death in donor lung injury. Transplantation 2003;75:1928-33.

18. Orens JB, Estenne M, Arcasoy S, et al. International guidelines for the selection of lung transplant candidates: 2006 update--a consensus report from the Pulmonary Scientific Council of the International Society for Heart and Lung Transplantation. J Heart Lung Transplant 2006;25:745-55.

19. Weill D, Benden C, Corris PA, et al. A consensus document for the selection of lung transplant candidates: 2014--an update from the Pulmonary Transplantation Council of the International Society for Heart and Lung Transplantation. J Heart Lung Transplant 2015;34:1-15.

20. Glazier AK, Delmonico FL, Koh HK. Organ Donation in the Era of the Opioid Crisis: A Clinical Strategy to Maximize Transplantation. Transplantation 2017;101:2652-4.

21. Weiner SG, Malek SK, Price CN. The Opioid Crisis and Its Consequences. Transplantation 2017;101:678-81.

22. Goldberg DS, Blumberg E, McCauley M, et al. Improving Organ Utilization to Help Overcome the Tragedies of the Opioid Epidemic. Am J Transplant 2016;16:2836-41.

23. Mehra MR, Jarcho JA, Cherikh W, et al. The DrugIntoxication Epidemic and Solid-Organ Transplantation. N Engl J Med 2018;378:1943-5.

24. Kramer AH, Zygun DA, Doig CJ, et al. Incidence of neurologic death among patients with brain injury: a cohort study in a Canadian health region. CMAJ 2013;185:E838-45.

25. Egan TM, Lambert CJ, Jr., Reddick R, et al. A strategy to increase the donor pool: use of cadaver lungs for transplantation. Ann Thorac Surg 1991;52:1113-20; discussion 1120-1.

26. D'Alessandro AM, Hoffmann RM, Knechtle SJ, et al. Successful extrarenal transplantation from non-heartbeating donors. Transplantation 1995;59:977-82.

27. Love RB, Stringham J, Chomiak PN, et al. First successful lung transplantation using a nonheart-beating donor (Abstract). J Heart Lung Transplant 1995;14:S88.

28. Wigfield CH, Love RB. Donation after cardiac death lung transplantation outcomes. Curr Opin Organ Transplant 2011;16:462-8.

29. Chancellor WZ, Charles EJ, Mehaffey JH, et al. Expanding the donor lung pool: how many donations after circulatory death organs are we missing? J Surg Res 2018;223:58-63.

30. Valapour M, Lehr CJ, Skeans MA, et al. OPTN/SRTR 2018 Annual Data Report: Lung. Am J Transplant 2020;20 Suppl s1:427-508. 
31. Krutsinger D, Reed RM, Blevins A, et al. Lung transplantation from donation after cardiocirculatory death: a systematic review and meta-analysis. J Heart Lung Transplant 2015;34:675-84.

32. Levvey BJ, Harkess M, Hopkins P, et al. Excellent clinical outcomes from a national donation-after-determinationof-cardiac-death lung transplant collaborative. Am J Transplant 2012;12:2406-13.

33. Choi AY, Jawitz OK, Raman V, et al. Predictors of nonuse of donation after circulatory death lung allografts. J Thorac Cardiovasc Surg 2021;161:458-66.e3.

34. Mooney JJ, Hedlin H, Mohabir PK, et al. Lung quality and utilization in controlled donation after circulatory determination of death within the United States. Am J Transplant 2016;16:1207-15.

35. Halpern SD. Donation after circulatory determination of death: time for transparency. Ann Emerg Med 2014;63:401-3.

36. Kurtz SF, Strong CW, Gerasimow D. The 2006 Revised Uniform Anatomical Gift Act - a law to save lives. Health Lawyers News; February 2007:44-9.

37. Parent B, Caplan A, Angel L, et al. The unique moral permissibility of uncontrolled lung donation after circulatory death. Am J Transplant 2020;20:382-8.

38. Dark JH, Egan TM. Lungs From the Controlled Donation After Circulatory Determination of Death Donor: Perspectives From the United States and Beyond. Am J Transplant 2016;16:1047-8.

39. Lindemann J, Dageforde LA, Vachharajani N, et al. Cost Evaluation of a Donation after Cardiac Death Program: How Cost per Organ Compares to Other Donor Types. J Am Coll Surg 2018;226:909-16.

40. Oto T, Levvey B, McEgan R, et al. A practical approach to clinical lung transplantation from a Maastricht Category III donor with cardiac death. J Heart Lung Transplant 2007;26:196-9.

41. Orens JB, Boehler A, de Perrot M, et al. A review of lung transplant donor acceptability criteria. J Heart Lung Transplant 2003;22:1183-200.

42. Cypel M, Sato M, Yildirim E, et al. Initial experience with lung donation after cardiocirculatory death in Canada. J Heart Lung Transplant 2009;28:753-8.

43. Mason DP, Brown CR, Murthy SC, et al. Growing singlecenter experience with lung transplantation using donation after cardiac death. Ann Thorac Surg 2012;94:406-11; discussion 411-2.

44. Levvey BJ, Westall GP, Kotsimbos T, et al. Definitions of warm ischemic time when using controlled donation after cardiac death lung donors. Transplantation 2008;86:1702-6.

45. Inci I, Hillinger S, Schneiter D, et al. Lung Transplantation with Controlled Donation after Circulatory Death Donors. Ann Thorac Cardiovasc Surg 2018;24:296-302.

46. De Oliveira NC, Osaki S, Maloney JD, et al. Lung transplantation with donation after cardiac death donors: long-term follow-up in a single center. J Thorac Cardiovasc Surg 2010;139:1306-15.

47. Van Raemdonck D, Keshavjee S, Levvey B, et al. Donation after circulatory death in lung transplantation-five-year follow-up from ISHLT Registry. J Heart Lung Transplant 2019;38:1235-45.

48. Ulicny Jr KS, Egan TM, Lambert Jr CJ, et al. Cadaver lung donors: effect of preharvest ventilation on graft function. Ann Thorac Surg 1993;55:1185-91.

49. Roberts CS, D'Armini AM, Egan TM. Canine doublelung transplantation with cadaveric donors. J Thorac Cardiovasc Surg 1996;112:577-83.

50. D'Armini AM, Roberts CS, Griffith PK, et al. When does the lung die? I. Histochemical evidence of pulmonary viability after "death". J Heart Lung Transplant 1994;13:741-7.

51. Alessandrini F, D'Armini AM, Roberts CS, et al. When does the lung die? II. Ultrastructural evidence of pulmonary viability after "death". J Heart Lung Transplant 1994;13:748-57.

52. Steen S, Sjoberg T, Pierre L, et al. Transplantation of lungs from a non-heart beating donor. Lancet 2001;357:825-9.

53. Nunez JR, Varela A, del Rio F, et al. Bipulmonary transplants with lungs obtained from two non-heartbeating donors who died out of hospital. J Thorac Cardiovasc Surg 2004;127:297-9.

54. Hoyert DL, Kung HC, Smith BL. Deaths: Preliminary data for 2003. Hyattsville, Md.: National Center for Health Statistics 2005.

55. American Heart Association. Cardiac Arrest Statistics. IN: Heart Disease and Stroke Statistics - 2013 Update, Available online: http://www.heart.org/HEARTORG/ General/Cardiac-Arrest-Statistics_UCM_448311_ Article.jsp.

56. Boyarsky BJ, Jackson KR, Kernodle AB, et al. Estimating the potential pool of uncontrolled DCD donors in the United States. Am J Transplant 2020;20:2842-6.

57. Egan TM, Wall S, Goldfrank L, et al. The real number of organs from uncontrolled donation after circulatory determination of death donors. Am J Transplant 2021;21:2301-2. 
58. NIH/NHLBI grant 1UM1HL113115. More and better lungs: Ex-vivo perfusion of lungs from non-heart-beating donors. 9/1/2013-8/31/2016.

59. Egan T, Blackwell J, Birchard K, et al. Assessment of Lungs for Transplant Recovered from Uncontrolled Donation after Circulatory Determination of Death Donors. Ann Am Thorac Soc 2017;14:S251.

60. Kochanek KD, Murphy SL, Xu JQ, et al. Deaths: Final data for 2017. National Vital Statistics Reports. Hyattsville, MD: National Center for Health Statistics; 2019.

61. Healey A, Watanabe Y, Mills C, et al. Initial lung transplantation experience with uncontrolled donation after cardiac death in North America. Am J Transplant 2020;20:1574-81.

62. Egan TM, Requard JJ, 3rd. Afterlife for lungs: A way to increase donor lungs for transplant. Am J Transplant 2020;20:2954-5.

63. de Antonio DG, Marcos R, Laporta R, et al. Results of clinical lung transplant from uncontrolled non-heartbeating donors. J Heart Lung Transplant 2007;26:529-34.

64. Gomez-de-Antonio D, Campo-Canaveral JL, Crowley S, et al. Clinical lung transplantation from uncontrolled nonheart-beating donors revisited. J Heart Lung Transplant 2012;31:349-53.

65. Lulla A, Svancarek B. Time To Stop Beating A Dead Horse: Termination Of Resuscitation In The Field. In: EMS MED. Available online: http://www.naemsp-blog. com/emsmed/2016/12/26/title-time-to-stop-beatinga-dead-horse-termination-of-resuscitation-in-the-field. Accessed 8/14/2020.

66. Libby C, Skinner RB, Rawal AR. EMS, Termination Of Resuscitation And Pronouncement of Death. In: StatPearls. StatPearls Publishing. 2020. Available online: https://www.ncbi.nlm.nih.gov/books/NBK541113/. Accessed 8/14/2020.

67. Dominguez-Gil B, Duranteau J, Mateos A, et al. Uncontrolled Donation after Circulatory Death: European practices and recommendations for the development and optimization of an effective programme. Transpl Int 2016;29:842-59.

68. Lomero M, Gardiner D, Coll E, et al. Donation after circulatory death today: an updated overview of the European landscape. Transpl Int 2020;33:76-88.

69. Minambres E, Rubio JJ, Coll E, et al. Donation after circulatory death and its expansion in Spain. Curr Opin Organ Transplant 2018;23:120-9.

70. Rega FR, Jannis NC, Verleden GM, et al. Should we ventilate or cool the pulmonary graft inside the non-heart- beating donor? J Heart Lung Transplant 2003;22:1226-33.

71. Valenza F, Citerio G, Palleschi A, et al. Successful transplantation of lungs from an uncontrolled donor after circulatory death preserved in situ by alveolar recruitment maneuvers and assessed by ex-vivo lung perfusion. Am J Transplant 2016;16:1312-8.

72. Egan TM. Lung Transplant From an Uncontrolled Donation After Circulatory Determination of Death Donor: Moving to Other Countries. Am J Transplant 2016;16:1051-2.

73. Suberviola B, Mons R, Ballesteros MA, et al. Excellent long-term outcome with lungs obtained from uncontrolled donation after circulatory death. Am J Transplant 2019;19:1195-201.

74. Egan TM, Requard JJ 3rd. Overcoming challenges of lung recovery from uDCDDs - Felicidades! Am J Transplant 2019;19:2391-2.

75. van Raemdonck D, Ceulemans LJ, Neyrinck A. Uncontrolled DCD lungs can survive the donor's death for an afterlife dimension in another body. Am J Transplant 2020;20:1475-6.

76. Palleschi A, Rosso L, Ruggeri GM, et al. Overcoming the Limits of Reconditioning: Seventeen Hours of Ex-Vivo Lung Perfusion (EVLP) with Successful Transplantation from Uncontrolled Circulatory Death Donor. Transplantation 2021. doi: 10.1097/ TP.0000000000003646.

77. Egan TM, Haithcock B, Ali MH, et al. A large animal model of ex-vivo lung perfusion as a platform to deliver therapeutic agents to lungs before lung transplant (Abstract). American journal of transplantation: official journal of the American Society of Transplantation and the American Society of Transplant Surgeons 2020;20:1131.

78. Charles EJ, Mehaffey JH, Sharma AK, et al. Lungs donated after circulatory death and prolonged warm ischemia are transplanted successfully after enhanced ex vivo lung perfusion using adenosine $\mathrm{A} 2 \mathrm{~B}$ receptor antagonism. J Thorac Cardiovasc Surg 2017;154:1811-20.

79. Bernat JL, Bleck TP, Blosser SA, et al. Circulatory death determination in uncontrolled organ donors: a panel viewpoint. Ann Emerg Med 2014;63:384-90.

80. Wall SP, Munjal KG, Dubler NN, et al. Uncontrolled organ donation after circulatory determination of death: US policy failures and call to action. Ann Emerg Med 2014;63:392-400.

81. Wall SP, Plunkett C, Caplan A. A Potential Solution to the Shortage of Solid Organs for Transplantation. JAMA 2015;313:2321-2. 
82. Volk ML, Warren GJ, Anspach RR, et al. Attitudes of the American public toward organ donation after uncontrolled (sudden) cardiac death. Am J Transplant 2010;10:675-80.

83. Egan TM, Requard JJ, Edwards TP. What does first person authorization (FPA) mean? Knowledge and attitudes among FPA adults re: Brain Dead donors (BDDs) and controlled Donation after Circulatory Determination of Death (cDCDD) donors. Understanding vs the law (Abstract). J Heart Lung Transplant 2017;36:S177.

84. Coll E, Minambres E, Sanchez-Fructuoso A, et al. Uncontrolled donation after circulatory death: a unique opportunity. Transplantation 2020;104:1542-52 .

85. Ceulemans LJ, Inci I, Van Raemdonck D. Lung donation after circulatory death. Curr Opin Organ Transplant 2019;24:288-96.

86. Egan TM, Requard JJ. Uncontrolled donation after circulatory determination of death donors (uDCDDs)

Cite this article as: Egan TM, Haithcock BE, Lobo J, Mody G, Love RB, Requard JJ 3rd, Espey J, Ali MH. Donation after circulatory death donors in lung transplantation. J Thorac Dis 2021;13(11):6536-6549. doi: 10.21037/jtd-2021-13 as a source of lungs for transplant. Am J Transplant 2015;15:2031-6.

87. Machuca TN, Mercier O, Collaud S, et al. Lung transplantation with donation after circulatory determination of death donors and the impact of ex vivo lung perfusion. Am J Transplant 2015;15:993-1002.

88. America DL. National donor designation report card. 2020. Available online: https://www.donatelife.net/ mission-vision/.

89. CDC. Current Cigarette Smoking Among Adults in the United States. 2020. Available online: https://www.cdc. gov/tobacco/data_statistics/fact_sheets/adult_data/cig_ smoking/index.htm.

90. Woolley AE, Singh SK, Goldberg HJ, et al. Heart and Lung Transplants from HCV-Infected Donors to Uninfected Recipients. N Engl J Med 2019;380:1606-17. 